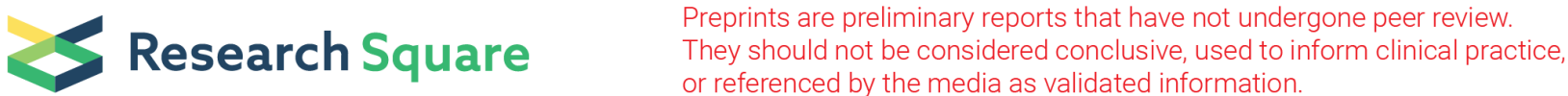

\section{Quality Of End-Of-Life Care In General Practice - A Pre-Post Comparison Of A Two-Tiered Intervention}

\author{
Katharina van Baal ( $\square$ vanbaal.katharina@mh-hannover.de) \\ Institute for General Practice and Palliative Care, Hannover Medical School \\ Birgitt Wiese \\ Institute for General Practice and Palliative Care, Hannover Medical School \\ Gabriele Müller-Mundt \\ Institute for General Practice and Palliative Care, Hannover Medical School \\ Stephanie Stiel \\ Institute for General Practice and Palliative Care, Hannover Medical School \\ Nils Schneider \\ Institute for General Practice and Palliative Care, Hannover Medical School \\ Kambiz Afshar \\ Institute for General Practice and Palliative Care, Hannover Medical School
}

\section{Research Article}

Keywords: General practice, primary care, end-of-life care, palliative care, health services research, quality of health care

Posted Date: February 23rd, 2022

DOI: https://doi.org/10.21203/rs.3.rs-1323440/v1

License: () (i) This work is licensed under a Creative Commons Attribution 4.0 International License. Read Full License 


\section{Abstract}

Background: General practitioners (GPs) play a crucial role in the provision of end-of-life care (EoLC). The present study aimed at comparing the quality of GPs' EoLC before and after an intervention involving a clinical decision aid and a public campaign.

Methods: The study was part of the larger interventional study 'Optimal care at the end of life' (OPAL) (Innovation Fund, Grant No. 01VSF17028). The intervention lasted 12 months and comprised two components: (1) implementation of the Supportive and Palliative Care Indicators Tool (SPICT-DE ${ }^{\mathrm{TM}}$ ) in general practice and (2) a public campaign in two German counties to inform and connect regional health care providers and stakeholders in EoLC. Participating GPs completed the General Practice End of Life Care Index (GPEoLC-I) pre- (t0) and post- (t1) intervention. The GP-EoLC-I (25 items, score range: 14-40) is a self-assessment questionnaire that measures the quality of GPs' EoLC. It includes two subscales: practice organisation and clinical practice. Data were analysed descriptively, and a paired t-test was applied for the pre-post comparison.

Results: Forty-five GPs (female: $29 \%$, median age: 57 years) from 33 general practices participated in the intervention and took part in the survey at both times of measurement ( $\mathrm{t} 0$ and $\mathrm{t} 1)$. The mean GP-EoLC-I score $(\mathrm{t} 0=27.9 ; \mathrm{t} 1=29.8)$ increased significantly by 1.9 points between $\mathrm{t} 0$ and $\mathrm{t} 1(\mathrm{t}(44)=-3.0 ; \mathrm{p}=0.005)$. Scores on the practice organisation subscale $(\mathrm{t} 0=6.9 ; \mathrm{t} 1=7.6)$ remained almost similar $(\mathrm{t}(44)=-2.0 ; \mathrm{p}=0.057)$, whereas those of the clinical practice subscale $(\mathrm{t} 0=21.0 ; \mathrm{t} 1=22.2)$ changed significantly between t0 and $\mathrm{t} 1(\mathrm{t}(44)=-2.6 ; \mathrm{p}=0.011)$. In particular, items regarding the record of care plans, patients' preferred place of care at the end of life and patients' preferred place of death, as well as the routine documentation of impending death, changed positively.

Conclusions: GPs' self-assessed quality of EoLC seemed to improve after a regional intervention that involved both the implementation of the SPICT-DE ${ }^{\mathrm{TM}}$ in daily practice and a public campaign. In particular, improvement related to the domains of care planning and documentation.

Trial registration: The study was registered in the German Clinical Trials Register (DRKS00015108; 22/01/2019).

\section{Background}

Palliative care needs at the end of life

International data suggest that approximately $75 \%$ of all people at the end of life are in need of palliative care (PC) [1]. In 2019, approximately 940,000 people died in Germany [2]. In the German context, outpatient PC is commonly separated into generalist and specialist outpatient PC $[3,4]$. The vast majority of people at the end of life can be cared for within the framework of generalist outpatient PC, which is typically provided by general practitioners (GPs) [3]. Thus, GPs play a key role in outpatient PC and end-of-life care (EoLC) $[5,6]$.

Quality of end-of-life care

Quality indicators are regularly applied to measure the quality of EoLC [7-10]. In Germany, specialist outpatient PC has increased in recent years, while the provision of generalist outpatient PC is rare and declining $[11,12]$. In addition, generalist outpatient PC tends to be provided relatively late in the care trajectory [11]. The early identification of patients with PC needs is particularly challenging for GPS in daily practice due to, among other reasons, prognostic uncertainty [13-15]. In this context, the Supportive and Palliative Care Indicators Tool (SPICT ${ }^{T M}$ ) [16] can support the systematic identification of patients with PC needs. A version of this tool is available for the German-speaking area (SPICT-DE ${ }^{T M}$ ) [17], and it was applied as part of the intervention in the present study. Additionally, the study included the General Practice End of Life Care Index (GP-EoLC-I), which is a specific measure of the quality of GPs' EoLC $[18,19]$.

\section{Preliminary work}

The 'Optimal care at the end of life' (OPAL) study is a Medical Research Council (MRC) phase-I study for complex interventions [20]. Employing a mixed-methods and pre-post design, the study aims at improving the provision of outpatient PC by GPs and health care providers for patients in their last phase of life [21]. Phase 1 of the OPAL study assessed standard PC provision in two counties in Lower Saxony (baseline, t0) [21]. A key component of this research was a standardised written survey of GPs to evaluate the quality of their EoLC from their own perspectives [22]. The t0 results indicated potential for improvement regarding the systematic identification of patients with potential PC needs, the realisation of multi-disciplinary case conferences to discuss patients with PC needs, the routine application of care protocols and symptom assessment tools, the documentation of patients' wishes and beliefs around EoLC, and the 
inclusion of informal caregivers [22]. GPs highlighted coordination and cooperation between stakeholders in EoLC as the most relevant indicators of good PC [22]. Furthermore, they identified the use of standardised tools (e.g. those used to systematically identify patients with potential PC needs) as an important requirement for improving the quality of PC [22].

Phase 2 included a regional intervention, which implemented both the SPICT-DE ${ }^{\mathrm{TM}}[17,23]$ in general practices and a public campaign to connect stakeholders and health care providers involved in EoLC [21]. In phase 3, the standard provision of PC was re-assessed (followup, t1) to facilitate a comparison between t0 and $\mathrm{t} 1$ and to investigate the potential effects of the intervention [21].

\section{Research gap, objective and research questions}

At the end of phase 2, it remained unclear whether the implementation of the SPICT-DE ${ }^{\mathrm{Tm}}$ (to support the identification of patients with potential PC needs in general practice) and a public campaign to improve collaboration and cooperation between stakeholders had impacted the quality of EoLC provided by GPs. Thus, the main objective of the present study was to compare the quality of GPs' EoLC before and after the intervention. Specifically, the following research questions were addressed:

- How did the two-tiered regional intervention influence the quality of GPs' EoLC?

- Which items of the GP-EoLC-I showed significant differences in the pre-post comparison?

\section{Methods \\ Study design}

The present study was part of OPAL [21] - an MRC phase-I prospective interventional mixed-methods study with a pre-post design.

\section{Setting}

Due to its regional approach, OPAL was realised in two counties in Lower Saxony, Germany. Both counties are so-called 'local health regions' with a special interest in facilitating cooperation between health care providers [24].

\section{Study population and recruitment}

The main study population consisted of practicing GPs in both counties in Lower Saxony. Based on the recruitment rates of previous studies, a sample size was calculated in advance of recruitment [21]. A power analysis detected a medium effect of the intervention for a sample of $50 \mathrm{GPs}$. Furthermore, a sample size of $50 \mathrm{GPs}$ was determined to have approximately $80 \%$ power to indicate an average difference of four points in the comparison between t0 and t1 (10 points standard deviation (SD) assumed; paired t-test, two-sided significance level of $5 \%)[18,21]$.

In October 2018, all registered GPs ( $=190$ GPs in $n=124$ general practices), excluding those only treating privately insured patients, were invited to take part in the study. Requests were maintained via phone, letter and fax until a response was recorded by each general practice. During the recruitment, brief and clear study information was sent to the general practices - if necessary, repeatedly. The recruitment phase ended in April 2019 [22].

Additionally, clinical data regarding patients with chronic, progressive disease (aged $\geq 18$ years and with statutory health insurance) who died between April and September 2018 (t0) or 2020 (t1) while receiving medical treatment by the participating GPs were gathered.

\section{Survey}

A standardised written survey of the quality of GPs' EoLC was administered at t0 (between October 2018 and May 2019) [22] and t1 (between October 2020 and March 2021), using the German version of the GP-EoLC-I (i.e. the main target variable in OPAL). The GPEoLC-I was developed at the University of Sheffield [18] and systematically translated, tested and adjusted for the German context by the Institute for General Practice and Palliative Care at Hannover Medical School [19].

The GP-EoLC-I measures GPs' perceptions of the quality of their PC and EoLC [18]. Scores for two subscales, practice organisation (12 items; score range: 1-14) and clinical care (13 items; score range: 13-26), are summarised to create an index score (25 items, score range 14-40), with higher scores indicating higher quality of EoLC. The original version of the GP-EoLC-I was found to demonstrate satisfactory internal consistency and reliability [18]. More details regarding the GP-EoLC-I and its German version can be found elsewhere $[18,19]$. To collect additional data on the participating general practices (i.e. structural characteristics), a semi-structured

Page $3 / 14$ 
questionnaire was also administered. For each general practice, the questionnaire was completed both before (t0) and after ( $\mathrm{t} 1)$ the intervention.

\section{Clinical data}

Medical assistants or GPs collected clinical data pertaining to the deceased patients, using their electronic or analogue documentation systems. In addition to patients' sociodemographic data (i.e. age, sex, date of death, diagnoses in the four quarters prior to death), the following data regarding the provision of generalist and specialist PC were assessed:

- number of patients receiving generalist outpatient PC in the last year of life;

- onset of generalist outpatient PC prior to death (in days);

- number of patients receiving specialist outpatient PC in the last year of life; and

- onset of specialist outpatient PC prior to death (in days).

The results regarding the clinical data assessed at t0 (with respect to patients who died between April and September 2018) have been published elsewhere [25]. In this article, the clinical data of patients who died between April and September 2020 ( $\mathrm{t} 1$ ) are used to describe the patient population treated in the general practices, in comparison to t0 data.

\section{Intervention}

The intervention lasted 12 months (from April/May 2019 to April/May 2020) and comprised two components: (1) the implementation of the SPICT-DE ${ }^{\text {m' }}$ in general practice and (2) a public campaign to inform and connect EoLC health care providers and stakeholders in both counties.

1. Intervention in general practices (i.e. SPICT-DE ${ }^{\text {m" }}$ )

The SPICT $^{\text {TM }}$ is a clinical tool that was developed in 2010 by the Primary Palliative Care Research Group at the University of Edinburgh, as part of the Gold Standards Framework in the United Kingdom [18]. It aims at supporting the identification of patients with deteriorating health and potentially unmet PC needs $[17,26]$. The German version of the SPICT ${ }^{T M}$ (SPICT-DE ${ }^{T M}$ ) was systematically translated and adjusted by the Institute for General Practice and Palliative Care at Hannover Medical School [17].

Each participating GP received standardised training in using the SPICT-DE' ${ }^{T M}$, alongside an in-depth definition of the term 'palliative care', in an appointment lasting approximately 30 minutes. In more detail, the user training conveyed information on the aim and background of using the SPICT-DE ${ }^{\mathrm{TM}}$ (according to the published guide) [27]; the intervention process, itself; when and how to use the SPICT-DE ${ }^{\mathrm{Tm}}$; and the documentation and inclusion and exclusion criteria for patients to be assessed with the SPICT-DE ${ }^{\mathrm{Tm}}$.

After completing the user training, GPs received a manual containing the most important information. They were asked to apply the SPICT-DE ${ }^{T M}$ in their daily practice for a duration of 12 months, with every patient aged $\geq 18$ years with chronic, progressive disease, seen in the practice or in the patient's home. Patients who were already receiving specialist outpatient PC and hospice residents were excluded. During the intervention phase, the study team scheduled three monitoring visits with reflection talks in each general practice every 4 months, to observe the implementation of the SPICT-DE ${ }^{T M}$ and to discuss emerging questions. The third monitoring visit was simultaneous with the end of the intervention phase.

2. Health region intervention (i.e. public campaign)

To inform EoLC stakeholders and health care providers in both counties, the study intervention implemented a public campaign. Through flyers, newsletters and articles published in the local press, the study team informed stakeholders about the study aims and the implementation of the SPICT-DE ${ }^{T M}$ in general practices. Furthermore, a multidisciplinary discussion panel ("health dialogue") was held in February 2020, aimed at the development of strategies to improve EoLC and better connect scientific work and practice in both regions.

\section{Data analysis}

Data were analysed using version 26 of the Statistical Package for Social Sciences (SPSS Inc., Chicago, IL/USA). Descriptive analyses included the calculation of means, SDs, medians and interquartile ranges (IQR). Clinical data of the deceased patients were analysed descriptively. Missing values were not replaced. Smaller sample sizes were stated for all items, indicating missing values. The 25 items comprising the GP-EoLC-I score contained no missing data. A paired t-test was used for the pre-post comparison of the GP-EoLC-I 
score, subscale scores and single item scores. Data regarding GPs who dropped out between timepoints were excluded from the analysis.

\section{Ethics and data protection}

The study was approved by the Ethics Committee of the Hannover Medical School in August 2018 (No. : 8038_BO_K_2018) and all methods were performed in accordance with the Declaration of Helsinki. Only pseudonymised data were analysed. The present study followed the data security procedure described in the study protocol of the main study OPAL [21].

\section{Results}

At t0, 52 GPs from 34 general practices participated in the study (recruitment rate of $27.4 \%$ of all eligible general practices). At $t 1,45$ GPs from 33 general practices took part in the post-intervention survey (Fig. 1).

\section{Description of the study sample}

A total of 45 GPs from 33 general practices participated in the survey at t0 and t1. Thirty-two male (71.1\%) and 13 female (28.9\%) GPs were included in the study sample. Participating GPs were aged $31-79$ years with a mean age of 55 years $(N=44 ; S D=10.4)$. More than half of the GPs worked in single practices (51.1\%). The median duration of their clinical practice was 28 years $(N=41 ; I Q R=20.0-$ 32.0) as a physician and 20 years $(I Q R=11.0-25.5)$ as a GP. Table 1 presents further information on the study sample.

Table 1

Description of the study sample $(\mathrm{n}=45 \mathrm{GPs})$

\begin{tabular}{|c|c|c|c|}
\hline Variable & & $\mathbf{n}$ & $\%$ \\
\hline \multirow[t]{4}{*}{ Practice form } & Single practice & 23 & 51.1 \\
\hline & Group practice & 18 & 40.0 \\
\hline & Joint practice & 3 & 6.7 \\
\hline & Medical care centre & 1 & 2.2 \\
\hline \multirow[t]{3}{*}{ Care region } & Medium-sized city & 18 & 40.0 \\
\hline & Small town & 13 & 28.9 \\
\hline & Rural community & 14 & 31.1 \\
\hline \multirow[t]{2}{*}{ Part of a teaching practice } & Yes & 15 & 33.3 \\
\hline & No & 30 & 66.7 \\
\hline \multirow[t]{3}{*}{ Palliative care qualification ${ }^{*}$} & Basic course & 15 & 33.3 \\
\hline & Additional qualification (incl. basic course) & 9 & 20.0 \\
\hline & Other qualification (e.g. experience on a PC ward) & 7 & 15.6 \\
\hline \multirow{5}{*}{$\begin{array}{l}\text { Activity in a palliative care initiative }{ }^{*} \\
\text { (multiple responses possible) }\end{array}$} & Hospice association & 5 & 11.1 \\
\hline & Quality circle & 8 & 17.8 \\
\hline & Palliative network & 4 & 8.9 \\
\hline & Specialist outpatient palliative care team & 11 & 24.4 \\
\hline & Other initiative & 2 & 4.4 \\
\hline
\end{tabular}

\section{Clinical data of the deceased patients}

At t0, data pertaining to 302 deceased patients ( $48 \%$ female) from 32 general practices were included in the analyses. Patients' median age at death was 82 years $(I Q R=73-87 ; n=300)$. The 11 analyses included data pertaining to 154 deceased patients $(54.5 \%$ female; 
median age at death: 84 years; IQR = 77-89) from 23 general practices. Table 2 displays the EoLC indicators based on the clinical data of the deceased patients, describing the patient population treated in the participating general practices.

Table 2

Provision and onset of generalist and specialist palliative care for patients at the participating general practices who died in 2018 and 2020

\begin{tabular}{|c|c|c|c|c|c|}
\hline \multirow[t]{2}{*}{ Indicator } & & \multicolumn{2}{|l|}{ to } & \multicolumn{2}{|l|}{$\mathrm{t} 1$} \\
\hline & & $\mathrm{n}$ & $\%$ & $\mathrm{n}$ & $\%$ \\
\hline \multirow{3}{*}{$\begin{array}{l}\text { Number of patients receiving generalist outpatient PC } \\
(\mathrm{t} 0: \mathrm{N}=302 ; \mathrm{t} 1: \mathrm{N}=154)\end{array}$} & yes & 85 & 28.1 & 33 & 21.4 \\
\hline & no & 215 & 71.2 & 117 & 76.0 \\
\hline & missing value & 2 & 0.7 & 4 & 2.6 \\
\hline \multirow{9}{*}{$\begin{array}{l}\text { Onset of generalist outpatient PC prior to death (in days) } \\
\text { (t0: } \mathrm{N}=85 ; \mathrm{t} 1: \mathrm{N}=33 \text { ) }\end{array}$} & $0-3$ & 10 & 11.8 & 3 & 9.1 \\
\hline & $4-10$ & 13 & 15.3 & 3 & 9.1 \\
\hline & $11-20$ & 11 & 12.9 & 3 & 9.1 \\
\hline & $21-30$ & 7 & 8.2 & 0 & 0.0 \\
\hline & $31-60$ & 9 & 10.6 & 3 & 9.1 \\
\hline & $61-120$ & 7 & 8.2 & 3 & 9.1 \\
\hline & $121-240$ & 5 & 5.9 & 5 & 15.1 \\
\hline & $\geq 241$ & 10 & 11.8 & 4 & 12.1 \\
\hline & missing value & 13 & 15.3 & 9 & 27.3 \\
\hline \multirow{3}{*}{$\begin{array}{l}\text { Number of patients receiving specialist outpatient PC } \\
\text { (t0: } \mathrm{N}=302 ; \mathrm{t} 1: \mathrm{N}=154 \text { ) }\end{array}$} & yes & 56 & 18.5 & 35 & 22.7 \\
\hline & no & 241 & 79.8 & 115 & 74.7 \\
\hline & missing value & 5 & 1.7 & 4 & 2.6 \\
\hline \multirow{9}{*}{$\begin{array}{l}\text { Onset of specialist outpatient PC prior to death (in days)* } \\
\text { (t0: } N=56 ; \mathrm{t} 1: \mathrm{N}=35 \text { ) }\end{array}$} & $0-3$ & 4 & 7.1 & 3 & 8.6 \\
\hline & $4-10$ & 12 & 21.4 & 7 & 20.0 \\
\hline & $11-20$ & 4 & 7.1 & 2 & 5.7 \\
\hline & $21-30$ & 9 & 16.1 & 2 & 5.7 \\
\hline & $31-60$ & 8 & 14.3 & 3 & 8.6 \\
\hline & $61-120$ & 10 & 17.9 & 5 & 14.3 \\
\hline & $121-240$ & 3 & 5.4 & 0 & 0.0 \\
\hline & $\geq 241$ & 3 & 5.4 & 5 & 14.3 \\
\hline & missing value & 3 & 5.4 & 8 & 22.9 \\
\hline
\end{tabular}

\section{GP-EoLC-I: Descriptive analyses}

The mean GP-EoLC-I score at t0 was $27.9(\mathrm{SD}=4.2)$ and, at t1, $29.8(\mathrm{SD}=4.2)$, considering the $45 \mathrm{GPs}$ who participated at both t0 and t1. The practice organisation subscale scores (Table 3) had a mean value of 6.9 at t0 (SD =2.1) and 7.6 at t1 (SD $=2.3)$. The clinical care subscale scores (Table 4$)$ had a mean value of 21.0 at t0 $(S D=3.1)$ and 22.2 at t1 $(S D=2.5)$. Tables 3 and 4 display the results for each item of the two subscales, comparing data between t 0 and $\mathrm{t} 1$. 
Table 3

GP-EoLC-I practice organisation subscale items $[18,19]$ at t0 and t1 ( $N=45$ GPs)

\begin{tabular}{|c|c|c|c|c|c|}
\hline \multirow[t]{2}{*}{ Item } & & \multicolumn{2}{|l|}{ to } & \multicolumn{2}{|l|}{ t1 } \\
\hline & & $\mathbf{n}$ & $\%$ & $\mathbf{n}$ & $\%$ \\
\hline \multirow[t]{5}{*}{ Systematic identification in the case file } & Never & 21 & 46.7 & 13 & 28.9 \\
\hline & Sometimes & 11 & 24.4 & 11 & 24.4 \\
\hline & Mostly & 8 & 17.8 & 16 & 35.6 \\
\hline & Always & 5 & 11.1 & 5 & 11.1 \\
\hline & & $\begin{array}{l}\text { Yes [n } \\
(\%)]\end{array}$ & $\begin{array}{l}\text { No }[n \\
(\%)]\end{array}$ & $\begin{array}{l}\text { Yes [n } \\
(\%)]\end{array}$ & $\begin{array}{l}\text { No }[n \\
(\%)]\end{array}$ \\
\hline \multirow[t]{6}{*}{ Inclusion criteria for PC register } & Cancer diagnosis & 37 & \multirow{2}{*}{$\begin{array}{l}8 \\
(17.8)\end{array}$} & \multirow{2}{*}{$\begin{array}{l}40 \\
(88.9)\end{array}$} & $5(11.1)$ \\
\hline & Life-limiting non-malignant disease & \multirow{2}{*}{$\begin{array}{l}35 \\
(77.8)\end{array}$} & & & $1(2.2)$ \\
\hline & Terminal disease & & $\begin{array}{l}10 \\
(22.2)\end{array}$ & $\begin{array}{l}44 \\
(97.8)\end{array}$ & $0(0.0)$ \\
\hline & $\begin{array}{l}\text { Increasing need for nursing and help in } \\
\text { everyday life }\end{array}$ & $\begin{array}{l}43 \\
(95.6)\end{array}$ & \multirow{2}{*}{$\begin{array}{l}2(4.4) \\
34 \\
(75.6)\end{array}$} & $\begin{array}{l}45 \\
(100.0)\end{array}$ & $\begin{array}{l}31 \\
(68.9)\end{array}$ \\
\hline & \multirow[t]{2}{*}{ None of these } & $\begin{array}{l}11 \\
(24.4)\end{array}$ & & $\begin{array}{l}14 \\
(31.1)\end{array}$ & \multirow{2}{*}{$\begin{array}{l}45 \\
(100.0)\end{array}$} \\
\hline & & $1(2.2)$ & $\begin{array}{l}44 \\
(97.8)\end{array}$ & $0(0.0)$ & \\
\hline \multirow{7}{*}{$\begin{array}{l}\text { Multi-disciplinary forum for discussing } \\
\text { PC patients }\end{array}$} & Formal regular meeting & $3(6.7)$ & \multirow{2}{*}{$\begin{array}{l}42 \\
(93.3)\end{array}$} & $7(15.6)$ & \multirow{2}{*}{$\begin{array}{l}38 \\
(84.4)\end{array}$} \\
\hline & Formal occasional meeting & $3(6.7)$ & & $9(20.0)$ & \\
\hline & Informal regular discussions & $6(13.3)$ & $\begin{array}{l}42 \\
(93.3)\end{array}$ & 10 & $\begin{array}{l}36 \\
(80.0)\end{array}$ \\
\hline & Ad hoc liaison & 28 & $\begin{array}{l}39 \\
(867)\end{array}$ & 25 & 35 \\
\hline & None of these & & & (55.6) & \\
\hline & & $(24.4)$ & $(37.8)$ & $7(15.6)$ & $(44.4)$ \\
\hline & & & $\begin{array}{l}34 \\
(75.6)\end{array}$ & & $\begin{array}{l}38 \\
(84.4)\end{array}$ \\
\hline System for coordinating PC & & $\begin{array}{l}15 \\
(33.3)\end{array}$ & $\begin{array}{l}30 \\
(66.7)\end{array}$ & $\begin{array}{l}17 \\
(37.8)\end{array}$ & $\begin{array}{l}28 \\
(62.2)\end{array}$ \\
\hline Named coordinator for PC & & $6(13.3)$ & $\begin{array}{l}39 \\
(86.7)\end{array}$ & $7(15.6)$ & $\begin{array}{l}38 \\
(84.4)\end{array}$ \\
\hline Unified regional record of PC patients & & $\begin{array}{l}13 \\
(28.9)\end{array}$ & $\begin{array}{l}32 \\
(71.1)\end{array}$ & $\begin{array}{l}10 \\
(22.2)\end{array}$ & $\begin{array}{l}35 \\
(77.8)\end{array}$ \\
\hline System to ensure $24 \mathrm{~h}$ availability of antic & atory med. & $\begin{array}{l}35 \\
(77.8)\end{array}$ & $\begin{array}{l}10 \\
(22.2)\end{array}$ & $\begin{array}{l}38 \\
(84.4)\end{array}$ & $7(15.6)$ \\
\hline Use of a protocol for the care of dying car & er patients & $\begin{array}{l}14 \\
(31.1)\end{array}$ & $\begin{array}{l}31 \\
(68.9)\end{array}$ & $\begin{array}{l}13 \\
(28.9)\end{array}$ & $\begin{array}{l}32 \\
(71.1)\end{array}$ \\
\hline Use of a symptom assessment tool for $P C$ & atients & $5(11.1)$ & $\begin{array}{l}40 \\
(88.9)\end{array}$ & $6(13.3)$ & $\begin{array}{l}39 \\
(86.7)\end{array}$ \\
\hline
\end{tabular}


Table 4

GP-EoLC-I clinical care subscale items $[18,19]$ at t0 and t 1 ( $N=45 \mathrm{GPs})$

\begin{tabular}{|c|c|c|c|c|c|c|c|c|}
\hline & to n (\%) & & & & t1 n (\%) & & & \\
\hline Item & Always & Mostly & $\begin{array}{l}\text { Some- } \\
\text { times }\end{array}$ & $\begin{array}{l}\text { Rarely/ } \\
\text { never }\end{array}$ & Always & Mostly & $\begin{array}{l}\text { Some- } \\
\text { times }\end{array}$ & $\begin{array}{l}\text { Rarely/ } \\
\text { never }\end{array}$ \\
\hline Record care plans for PPC* & $\begin{array}{l}15 \\
(33.3)\end{array}$ & $\begin{array}{l}15 \\
(33.3)\end{array}$ & $\begin{array}{l}6 \\
(13.3)\end{array}$ & $9(20.0)$ & $\begin{array}{l}23 \\
(51.1)\end{array}$ & $\begin{array}{l}17 \\
(37.8)\end{array}$ & $\begin{array}{l}2 \\
(4.4)\end{array}$ & $3(6.7)$ \\
\hline $\begin{array}{l}\text { Encourage PPC in preparing for death in an } \\
\text { active manner* }\end{array}$ & $\begin{array}{l}12 \\
(26.7)\end{array}$ & $\begin{array}{l}21 \\
(46.7)\end{array}$ & $\begin{array}{l}8 \\
(17.8)\end{array}$ & $4(8.9)$ & $\begin{array}{l}14 \\
(31.1)\end{array}$ & $\begin{array}{l}21 \\
(46.7)\end{array}$ & $\begin{array}{l}10 \\
(22.2)\end{array}$ & $0(0.0)$ \\
\hline Assist PPC by addressing unfinished business & $\begin{array}{l}7 \\
(15.6)\end{array}$ & $\begin{array}{l}29 \\
(64.4)\end{array}$ & $\begin{array}{l}5 \\
(11.1)\end{array}$ & $4(8.9)$ & $\begin{array}{l}12 \\
(26.7)\end{array}$ & $\begin{array}{l}20 \\
(44.4)\end{array}$ & $\begin{array}{l}13 \\
(28.9)\end{array}$ & $0(0.0)$ \\
\hline Assist PPC by preparing advance directives* & $\begin{array}{l}16 \\
(35.6)\end{array}$ & $\begin{array}{l}19 \\
(42.2)\end{array}$ & $\begin{array}{l}8 \\
(17.8)\end{array}$ & $2(4.4)$ & $\begin{array}{l}10 \\
(22.2)\end{array}$ & $\begin{array}{l}29 \\
(64.4)\end{array}$ & $\begin{array}{l}6 \\
(13.3)\end{array}$ & $0(0.0)$ \\
\hline Record PPC wishes or spiritual beliefs & $\begin{array}{l}8 \\
(17.8)\end{array}$ & $\begin{array}{l}13 \\
(28.9)\end{array}$ & $\begin{array}{l}10 \\
(22.2)\end{array}$ & $\begin{array}{l}14 \\
(31.1)\end{array}$ & $\begin{array}{l}12 \\
(26.7)\end{array}$ & $\begin{array}{l}13 \\
(28.9)\end{array}$ & $\begin{array}{l}11 \\
(24.4)\end{array}$ & $\begin{array}{l}9 \\
(20.0)\end{array}$ \\
\hline $\begin{array}{l}\text { Record preferred place of care at the end of life } \\
/ \text { death* }\end{array}$ & $\begin{array}{l}9 \\
(20.0)\end{array}$ & $\begin{array}{l}11 \\
(24.4)\end{array}$ & $\begin{array}{l}9 \\
(20.0)\end{array}$ & $\begin{array}{l}16 \\
(35.6)\end{array}$ & $\begin{array}{l}15 \\
(33.3)\end{array}$ & $\begin{array}{l}14 \\
(31.1)\end{array}$ & $\begin{array}{l}10 \\
(22.2)\end{array}$ & $\begin{array}{l}6 \\
(13.3)\end{array}$ \\
\hline $\begin{array}{l}\text { Routinely assess and discontinue inappropriate } \\
\text { interventions (incl. med.) }\end{array}$ & $\begin{array}{l}26 \\
(57.8)\end{array}$ & $\begin{array}{l}16 \\
(35.6)\end{array}$ & $1(2.2)$ & $2(4.4)$ & $\begin{array}{l}27 \\
(60.0)\end{array}$ & $\begin{array}{l}18 \\
(40.0)\end{array}$ & $\begin{array}{l}0 \\
(0.0)\end{array}$ & $0(0.0)$ \\
\hline $\begin{array}{l}\text { Record of a named family carer for discussion } \\
\text { and coordination of care* }\end{array}$ & $\begin{array}{l}23 \\
(51.1)\end{array}$ & $\begin{array}{l}15 \\
(33.3)\end{array}$ & $3(6.7)$ & $4(8.9)$ & $\begin{array}{l}23 \\
(51.1)\end{array}$ & $\begin{array}{l}20 \\
(44.4)\end{array}$ & $\begin{array}{l}2 \\
(4.4)\end{array}$ & $0(0.0)$ \\
\hline $\begin{array}{l}\text { Disseminate appropriate written information to } \\
\text { family and carers }\end{array}$ & $4(8.9)$ & $\begin{array}{l}5 \\
(11.1)\end{array}$ & $\begin{array}{l}11 \\
(24.4)\end{array}$ & $\begin{array}{l}25 \\
(55.6)\end{array}$ & $4(8.9)$ & $\begin{array}{l}12 \\
(26.7)\end{array}$ & $\begin{array}{l}18 \\
(40.0)\end{array}$ & $\begin{array}{l}11 \\
(24.4)\end{array}$ \\
\hline $\begin{array}{l}\text { Document the family's or carers' insights into } \\
\text { the patient's condition }\end{array}$ & $4(8.9)$ & $\begin{array}{l}18 \\
(40.0)\end{array}$ & $\begin{array}{l}13 \\
(28.9)\end{array}$ & $\begin{array}{l}10 \\
(22.2)\end{array}$ & $\begin{array}{l}8 \\
(17.8)\end{array}$ & $\begin{array}{l}17 \\
(37.8)\end{array}$ & $\begin{array}{l}11 \\
(24.4)\end{array}$ & $\begin{array}{l}9 \\
(20.0)\end{array}$ \\
\hline $\begin{array}{l}\text { Dispatch a handover form for out-of-hours care } \\
\text { for PPC* }\end{array}$ & $\begin{array}{l}11 \\
(24.4)\end{array}$ & $\begin{array}{l}15 \\
(33.3)\end{array}$ & $\begin{array}{l}13 \\
(28.9)\end{array}$ & $6(13.3)$ & $\begin{array}{l}11 \\
(24.4)\end{array}$ & $\begin{array}{l}17 \\
(37.8)\end{array}$ & $\begin{array}{l}11 \\
(24.4)\end{array}$ & $\begin{array}{l}6 \\
(13.3)\end{array}$ \\
\hline $\begin{array}{l}\text { Out-of-hours availability to PPC in terminal } \\
\text { stages of illness }\end{array}$ & $\begin{array}{l}17 \\
(37.8)\end{array}$ & $\begin{array}{l}12 \\
(26.7)\end{array}$ & $\begin{array}{l}11 \\
(24.4)\end{array}$ & $5(11.1)$ & $\begin{array}{l}18 \\
(40.0)\end{array}$ & $\begin{array}{l}12 \\
(26.7)\end{array}$ & $\begin{array}{l}9 \\
(20.0)\end{array}$ & $\begin{array}{l}6 \\
(13.3)\end{array}$ \\
\hline Routine documentation of impending death* & $\begin{array}{l}8 \\
(17.8)\end{array}$ & $\begin{array}{l}11 \\
(24.4)\end{array}$ & $\begin{array}{l}11 \\
(24.4)\end{array}$ & $\begin{array}{l}15 \\
(33.3)\end{array}$ & $\begin{array}{l}13 \\
(28.9)\end{array}$ & $\begin{array}{l}14 \\
(31.1)\end{array}$ & $\begin{array}{l}6 \\
(13.3)\end{array}$ & $\begin{array}{l}12 \\
(26.7)\end{array}$ \\
\hline
\end{tabular}

[Table 3 and Table 4 should be placed here]

\section{GP-EoLC-I: Comparison between t0 and t1}

A statistical comparison between t0 and t1 using the paired t-test showed a significant increase between timepoints for the GP-EoLC-I score, with a mean difference of 1.9 points $(t(44)=-3.0, p=0.005)$. Additionally, the clinical care subscale score differed significantly between $\mathrm{t} 0$ and $\mathrm{t} 1$, with a mean alteration of 1.2 points $(\mathrm{t}(44)=-2.6, \mathrm{p}=0.011)$; and the practice organisation subscale score varied insignificantly between timepoints, with a mean difference of 0.7 points $(t(44)=-2.0, p=0.057)$. In particular, items regarding the record of care plans, patients' preferred place of care at the end of life and patients' preferred place of death, as well as the routine documentation of impending death, showed positive changes (Table 4).

Public campaign and 'health dialogue'

During the regional intervention, three newsletters were sent to participating GPs, stakeholders and health care providers at the interfaces of general practice. In autumn 2019, the project, its aims and the intervention in general practices were presented at health events in both counties. The multidisciplinary discussion panel 'health dialogue' took place in February 2020, with 36 participants. Several GPs and their practice teams, regional PC stakeholders (e.g. staff of hospices, specialised PC services, inpatient PC units, nursing services) and political representatives of both health regions took part in the event. The 4-hour panel comprised two parts: (1) 
presentation of the OPAL phase 1 study results (i.e. evaluation phase t0) and (2) workshops with participants to discuss the results, develop strategies to improve EoLC and better link scientific work and practice in both regions.

The public campaign aimed at optimising collaboration between health care providers and PC professionals, and the positive feedback and responses of stakeholders suggest that the campaign was successful.

\section{Discussion}

The present study aimed at comparing the quality of GPs' EoLC before and after an intervention in two counties in Lower Saxony, Germany, that included: (1) the implementation of the SPICT-DE ${ }^{T M}$ in general practice as a clinical decision aid in identifying potential PC patients and (2) a public campaign to inform and connect EoLC stakeholders. To the best of our knowledge, OPAL is the first study to have assessed a regionwide implementation of the SPICT-DE ${ }^{T M}$ in general practices in Germany. According to the GP-EoLC-I, GPs' selfassessed quality of EoLC significantly improved after the intervention. In particular, items associated with the clinical care subscale regarding the record of care plans, patients' preferred place of care at the end of life and patients' preferred place of death, as well as the routine documentation of impending death, changed positively.

Compared to data from the United Kingdom in 2010 (mean 31.0) [18], GPs in our sample showed a lower GP-EoLC-I at t0 (with a difference of 3.1 points). After the intervention (t1), German GP scores approached those of the UK sample.

GPs often face difficulty identifying the adequate timepoint in a patient's disease trajectory to initiate PC. This difficulty is especially pronounced in the case of patients with chronic, non-malignant disease $[13,16]$. Although it is widely accepted that the timely identification of PC needs benefits patients $[16,28]$, the systematic identification of patients with potential PC needs in Germany remains inconsistent $[7,22]$.

Our results confirm earlier findings from different settings and populations, which identify the SPICT ${ }^{T M}$ as a practical and helpful tool to support the identification of patients who might benefit from PC $[17,26,29,30]$. The SPICT-DE ${ }^{\text {TM }}$ might also improve GPs' EoLC competencies and increase their awareness of the PC needs in general and particularly of patients with chronic, non-malignant disease [17]. Significant differences between t0 and $t 1$ were especially seen for items regarding the documentation of care plans. The SPICT$D E^{T M}$ facilitates the administration and documentation of care plans, as well as the documentation of patients' preferred place of care at the end of life and preferred place of death. These results emphasise the importance of patient-centred care and advance care planning (ACP).

It is crucial for health care providers to be confident in their decision making around ACP, in order to ensure a high quality of care [31, 32]. Advance care plans aim at bringing patients' preferences in line with EoLC [33]. Accordingly, they may contribute to optimising the quality of EoLC [32]. However, ACP documents are not regularly available when needed, and several barriers to ACP have been acknowledged [33-35]. In particular, patients might avoid talking about EoLC for various reasons (e.g. a lack of knowledge, misleading interpretation of the relevance of ACP) [34]. GPs often have very personal and long-standing relationships with patients, and are therefore highly eligible to address EoLC topics [34].

Previous studies have revealed major challenges in GPs' provision of EoLC. These include a need for more collaborative care and a lack of significant communication and cooperation between caregivers, stakeholders and patients [6,22,36,37]. The present study addressed collaboration and cooperation by conducting a public campaign and connecting health care providers and stakeholders. The results emphasise the importance of applying a two-tiered intervention, involving both GPs and regional stakeholders - underlining that the isolated clinical implementation of the SPICT-DE ${ }^{\text {TM }}$ may not be sufficient to produce significant change. However, the present study identified room for further improvement after the intervention, particularly with respect to communication and co-ordination, which represent two of the so-called 'seven Cs' in the Gold Standards Framework for primary care $[18,38]$. Thus, further steps to enhance GPs' EoLC may include the early integration of health care professionals to coordinate EoLC and the determination of an employee responsible for such coordination, as described in the GP-EoLC-I practice organisation subscale. Also, close cooperation between GPs, specialised outpatient PC teams and other services might improve GPs' EoLC $[39,40]$ and positively influence patient outcomes [41].

The inclusion of family caregivers in the provision of care is essential, as informal caregivers often provide the majority of EoLC [ 42 , 43]. The GP-EoLC-I underlines the importance of informal caregivers, as three items on the clinical care subscale address their inclusion in generalist PC: recording a named family carer to discuss and coordinate care, disseminating appropriate written information to family members and carers, and documenting family members' (and/or carers') insights into the patient's condition. Unfortunately, 
these items demonstrated potential for improvement at t0 and no significant improvement at t1. GPs support for family caregivers therefore represents a highly important field of action to improve GPs' EoLC, and this should be addressed in future research.

To implement the stated fields of action in generalist PC (i.e. the identification of patients with potential PC needs, communication, cooperation, the inclusion of family members and carers), GPs require appropriate working conditions. The high effort associated with GPs' daily practice of generalist outpatient PC is not sufficiently acknowledged in their remuneration. This represents a major barrier for the provision of generalist outpatient PC and the identification of PC needs [40]. Furthermore, time constraints and staff shortages represent additional obstacles to the provision of PC by GPs [44, 45]. Future research should address these factors and develop further strategies to improve the structural, legal and financial conditions for generalist PC in Germany [40]. A first step towards improvement might be the remuneration for applying the SPICT-DE ${ }^{\text {TM }}$ in Germany.

The regional implementation strategy and the intervention applied in OPAL might be transferred to other regions, to Lower Saxony at large and to other federal states. In order to facilitate this, the study results should be included in medical education as well as residency and specialised PC training for physicians and other health care professionals [21].

\section{Strengths And Limitations}

The present study represented the first attempt to use the GP-EoLC-I to compare the quality of GPs' EoLC before and after an intervention in Germany. Future studies might apply it to evaluate the quality of PC over time.

The results of the study relate to a selected region in Lower Saxony and cannot, therefore, be generalised unreservedly. The lack of a control group is a second important limitation, as it prevents us from concluding without reservation that the differences in the quality of GPs' EoLC were (only) caused by the intervention. Furthermore, a selection bias might have been present, to the extent that participating GPs may have had greater interest in PC, and their insights may have therefore differed from those of the collective group of GPs in Germany. Furthermore, EoLC quality was self-assessed only by the participating GPs, and no insights from patients or relatives were included.

Although the pre-post comparison of the GP-EoLC-I showed statistically significant differences, the clinical significance remains questionable. Further analyses within the OPAL study will focus on the perspectives of PC experts and the relatives of deceased patients in general practice [21].

\section{Conclusions}

The quality of GPs' EoLC seemed to improve after a two-tiered regional intervention including: (1) the implementation of a clinical decision aid for the identification of patients with potential PC needs in general practice and (2) a public campaign to inform and connect EOLC providers. The GP-EoLC-I is effective at assessing and comparing the quality of GPs' EoLC, as well as identifying potential areas for improvement.

\section{Abbreviations}

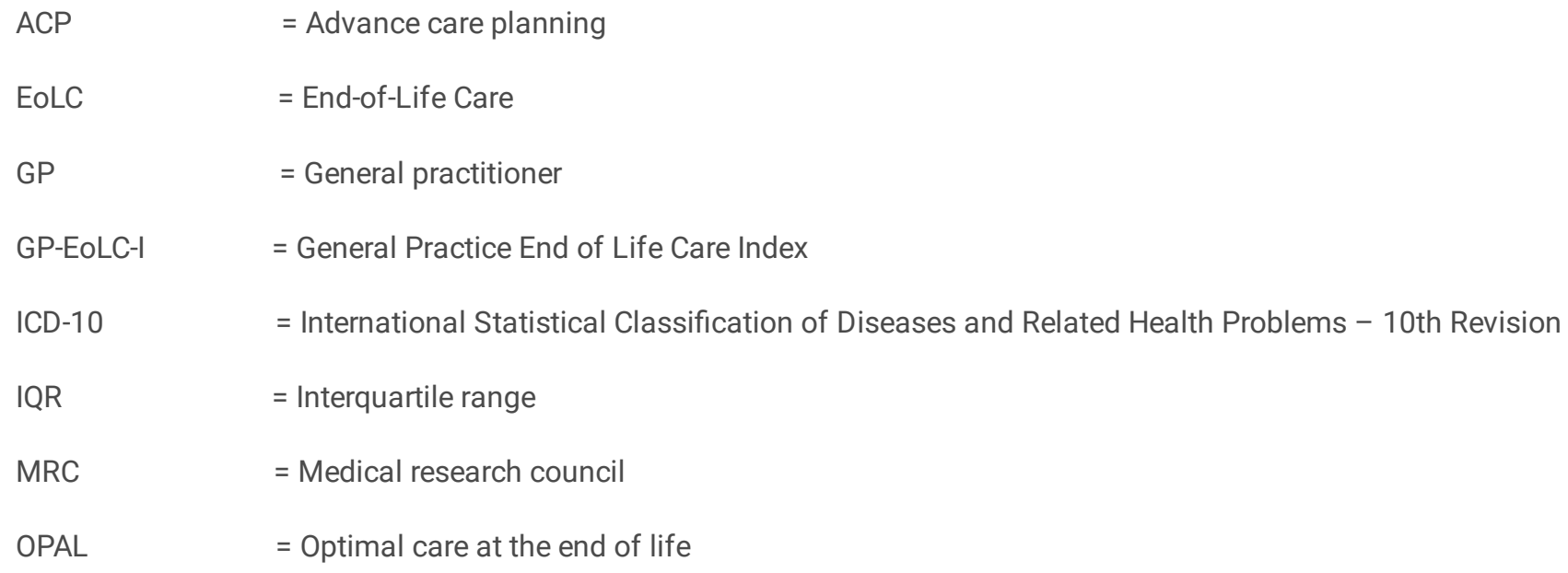




\section{Declarations}

Ethics approval and consent to participate

Ethics approval was granted by the ethics committee of Hannover Medical School on 16 August 2018, for the main OPAL study (Registration No 8038_BO_K_2018).

All GPs provided written informed consent prior to participation in any study procedure. All data were pseudonymised.

Consent for publication

Not applicable.

Availability of data and materials

The datasets generated and/or analysed during the current study are not publicly available due to data privacy protection regulations but are available from the corresponding author on reasonable request.

Competing interests

The authors declare that they have no competing interests.

Funding

The present study was part of the larger 'Optimal care at the end of life' (OPAL) study, funded by the Innovation Fund of the Federal Joint Committee (Innovationsfonds des Gemeinsamen Bundesausschusses, Grant No. 01VSF17028). The funding body had no influence on the study design, data collection, data analysis and interpretation, or manuscript preparation.

Author contributions

KA, GMM and NSch developed the original concept for the OPAL study, contributed substantially to the study design and provided relevant intellectual input. BW and SSt contributed to the methodology and data analysis. KvB and BW analysed the data. KvB and KA wrote the manuscript. All authors revised and approved the final manuscript.

Acknowledgments

We thank the study nurses Hannah Vollmer and Sonja Riedel-Schatte for supporting the data acquisition and data preparation. Furthermore, we thank all GPs and their practice teams for their willingness to participate in the study. We also thank Valerie Appleby for copy-editing the present manuscript.

\section{References}

1. Rosenwax LK, McNamara B, Blackmore AM, Holman CD. Estimating the size of a potential palliative care population. Palliat Med. 2005;19(7):556-62.

2. Statistisches Bundesamt. Daten der Lebendgeborenen, Totgeborenen, Gestorbenen und der Gestorbenen im 1. Lebensjahr. 2019. https://www.destatis.de/DE/Themen/Gesellschaft-Umwelt/Bevoelkerung/Geburten/Tabellen/lebendgeborene-gestorbene.html. Accessed 01 Feb 2022. 
3. Radbruch L, Payne S. White Paper on standards and norms for hospice and palliative care in Europe: Part 1. Eur J Palliat Care. 2010;17(1).

4. Busse R, Blumel M, Knieps F, Barnighausen T. Statutory health insurance in Germany: A health system shaped by 135 years of solidarity, self-governance, and competition. Lancet. 2017;390(10097):882-97.

5. Schnakenberg R, Goeldlin A, Boehm-Stiel C, Bleckwenn M, Weckbecker K, Radbruch L. Written survey on recently deceased patients in Germany and Switzerland: How do general practitioners see their role? BMC Health Serv Res. 2016;16:22.

6. Rhee JJ, Teo PCK, Mitchell GK, Senior HE, Tan AJH, Clayton JM. General practitioners (GPs) and end-of-life care: A qualitative study of Australian GPs and specialist palliative care clinicians. BMJ Support Palliat Care. 2018. DOI: 10.1136/bmjspcare-2018-001531 (online first).

7. Radbruch L, Andersohn F, Walker J. Faktencheck Gesundheit - Palliativversorgung Modul 3: Überversorgung kurativ Unterversorgung palliativ? Analyse ausgewählter Behandlungen am Lebensende. Gütersloh: Bertelsmann Stiftung; 2015. https://faktencheck-gesundheit.de/fileadmin/files/BSt/Publikationen/GrauePublikationen/Studie_VV_FCG_Ueber-Unterversorgungpalliativ.pdf. Accessed 01 Feb 2022.

8. De Schreye R, Houttekier D, Deliens L, Cohen J. Developing indicators of appropriate and inappropriate end-of-life care in people with Alzheimer's disease, cancer or chronic obstructive pulmonary disease for population-level administrative databases: A RAND/UCLA appropriateness study. Palliat Med. 2017;31(10):932-45.

9. De Roo ML, Leemans K, Claessen SJ, Cohen J, Pasman HR, Deliens L, et al. Quality indicators for palliative care: Update of a systematic review. J Pain Symptom Manage. 2013;46(4):556-72.

10. Dy SM, Kiley KB, Ast K, Lupu D, Norton SA, McMillan SC, et al. Measuring what matters: Top-ranked quality indicators for hospice and palliative care from the American Academy of Hospice and Palliative Medicine and Hospice and Palliative Nurses Association. $J$ Pain Symptom Manage. 2015;49(4):773-81.

11. van Baal K, Schrader S, Schneider N, Wiese B, Stahmeyer JT, Eberhard S, et al. Quality indicators for the evaluation of end-of-life care in Germany - A retrospective cross-sectional analysis of statutory health insurance data. BMC Palliat Care. 2020;19(1):187.

12. Ditscheid B, Krause M, Lehmann T, Stichling K, Jansky M, Nauck F, et al. Palliativversorgung am Lebensende in Deutschland. Bundesgesundheitsbl. 2020;63, 1502-1510.

13. Mulcahy P, Buetow S, Osman L, Coster G, Bray Y, White P, et al. GPs' attitudes to discussing prognosis in severe COPD: An Auckland (NZ) to London (UK) comparison. Fam Pract. 2005;22(5):538-40.

14. Kennedy C, Brooks-Young P, Brunton Gray C, Larkin P, Connolly M, Wilde-Larsson B, et al. Diagnosing dying: An integrative literature review. BMJ Support Palliat Care. 2014;4(3):263-70.

15. Pocock LV, Wye L, French LRM, Purdy S. Barriers to GPs identifying patients at the end-of-life and discussions about their care: A qualitative study. Fam Pract. 2019;36(5):639-43.

16. Boyd K, Murray SA. Recognising and managing key transitions in end of life care. BMJ. 2010;341:c4863.

17. Afshar K, Feichtner A, Boyd K, Murray S, Junger S, Wiese B, et al. Systematic development and adjustment of the German version of the Supportive and Palliative Care Indicators Tool (SPICT-DE). BMC Palliat Care. 2018;17(1):27.

18. Hughes PM, Bath PA, Ahmed N, Noble B. What progress has been made towards implementing national guidance on end of life care? A national survey of UK general practices. Palliat Med. 2010;24(1):68-78.

19. Afshar K, Herbst F, Tetzlaff F, Stiel S, Schneider N, Müller-Mundt G. Hausärztliche Begleitung in der letzten Lebensphase (HA-BeL): Systematische Entwicklung und Anpassung der deutschsprachigen Version des General Practice End of Life Care Index. Z Evide Fortbild Qual Gesundhwesen. 2020;153-154: 84-96. 
20. Craig P, Dieppe P, Macintyre S, Michie S, Nazareth I, Petticrew M, et al. Developing and evaluating complex interventions: The new Medical Research Council guidance. BMJ. 2008;337:a1655.

21. Afshar K, Müller-Mundt G, van Baal K, Schrader S, Wiese B, Bleidorn J, et al. Optimal care at the end of life (OPAL): Study protocol of a prospective interventional mixed-methods study with pretest-posttest-design in a primary health care setting considering the view of general practitioners, relatives of deceased patients and health care stakeholders. BMC Health Serv Res. 2019;19(1):486.

22. van Baal K, Schrader S, Wiese B, Geyer S, Stiel S, Schneider N, et al. GPs' perspective on End-of-Life Care - An evaluation based on the German version of the General Practice End of Life Care Index. Ger Med Sci. 2020;18(Doc10).

23. Highet G, Crawford D, Murray SA, Boyd K. Development and evaluation of the Supportive and Palliative Care Indicators Tool (SPICT): A mixed-methods study. BMJ Support Palliat Care. 2014;4(3):285-90.

24. Niedersächsisches Ministerium für Soziales, Gesundheit und Gleichstellung. Gesundheitsregionen Niedersachsen. 2022. https://www.ms.niedersachsen.de/startseite/gesundheit_pflege/gesundheit/gesundheitsregionen_niedersachsen/gesundheitsregionenniedersachsen-119925.html. Accessed 01 Feb 2022.

25. van Baal K, Schrader S, Schneider N, Wiese B, Stiel S, Afshar K. Versorgung von Menschen am Lebensende in einer ländlichkleinstädtischen Region

Niedersachsens: eine retrospektive Querschnittsanalyse auf Basis hausärztlicher Routinedaten. Z Evid Fortbild Qual Gesundhwesen. 2022; https://doi.org/10.1016/j.zefq.2021.10.002 (online first).

26. Afshar K, Müller-Mundt G, Schneider N. Wie können Patienten mit chronisch fortschreitenden nicht-onkologischen Erkrankungen erkannt werden, bei denen eine Palliativversorgung sinnvoll ist? Z Palliativmed. 2016;17(03):133-8.

27. The University of Edinburgh. Supportive and Palliative Care Indicators Tool - German version. 2019. https://www.spict.org.uk/thespict/spict-de/. Accessed 01 Feb 2022.

28. Thoonsen B, Groot M, Verhagen S, van Weel C, Vissers K, Engels Y. Timely identification of palliative patients and anticipatory care planning by GPs: Practical application of tools and a training programme. BMC Palliat Care. 2016;15:39.

29. Sulistio M, Franco M, Vo A, Poon P, William L. Hospital rapid response team and patients with life-limiting illness: A multicentre retrospective cohort study. Palliat Med. 2015;29(4):302-9.

30. De Bock R, Van Den Noortgate N, Piers R. Validation of the Supportive and Palliative Care Indicators Tool in a Geriatric Population. J Palliat Med. 2018;21(2):220-4.

31. Mistry B, Bainbridge D, Bryant D, Tan Toyofuku S, Seow H. What matters most for end-of-life care? Perspectives from communitybased palliative care providers and administrators. BMJ Open. 2015;5(6):e007492-e.

32. Fleuren N, Depla MFIA, Janssen DJA, Huisman M, Hertogh CMPM. Underlying goals of advance care planning (ACP): A qualitative analysis of the literature. BMC Palliat Care. 2020;19(1):27.

33. Panozzo L, Harvey P, Adams MJ, O'Connor D, Ward B. Communication of advance care planning decisions: A retrospective cohort study of documents in general practice. BMC Palliat Care. 2020;19(1):108.

34. Bernard C, Tan A, Slaven M, Elston D, Heyland DK, Howard M. Exploring patient-reported barriers to advance care planning in family practice. BMC Fam Pract. 2020;21(1):94.

35. Blackwood DH, Walker D, Mythen MG, Taylor RM, Vindrola-Padros C. Barriers to advance care planning with patients as perceived by nurses and other healthcare professionals: A systematic review. J Clin Nurs. 2019;28(23-24):4276-97.

36. Krug K, Ballhausen RA, Bölter R, Engeser P, Wensing M, Szecsenyi J, et al. Challenges in supporting lay carers of patients at the end of life: Results from focus group discussions with primary healthcare providers. BMC Fam Pract. 2018;19(1):112. 
37. Schrader S, van Baal K, Schleef T, Schneider N, Afshar K, Müller-Mundt G. „... das klassische Problem ist zu sagen, man ist ja jetzt palliativ" - Versorgung am Lebensende an den Schnittstellen zur hausärztlichen Versorgung in ländlich geprägten Regionen - eine qualitative multiperspektivische Studie. Z Palliativmed. 2020;21(06):309-15.

38. Amass C. The Gold Standards Framework for palliative care in the community. The Pharmaceutical Journal. 2006;276:353-4.

39. Behmann M, Junger S, Radbruch L, Schneider N. Public health actions to improve palliative care in Germany: Results of a threeround Delphi study. Health Policy. 2012;106(3):303-12.

40. Ewertowski H, Hesse AK, Schneider N, Stiel S. Primary palliative care provision by general practitioners: Development of strategies to improve structural, legal and financial framework conditions [in German]. Z Evid Fortbild Qual Gesundhwesen. 2020;149:32-39.

41. Afshar K, Geiger K, Müller-Mund G, Bleidorn J, Schneider N. Hausärztliche Palliativversorgung bei nichtonkologischen Patienten. Eine Übersichtsarbeit. Schmerz. 2015;29:604-15.

42. Burns CM, Abernethy AP, Dal Grande E, Currow DC. Uncovering an invisible network of direct caregivers at the end of life: A population study. Palliat Med. 2013;27(7):608-15.

43. Adejoh So, Boele F, Akeju D, Dandadzi A, Nabirye E, Namisango E, et al. The role, impact, and support of informal caregivers in the delivery of palliative care for patients with advanced cancer: A multi-country qualitative study. Palliat Med. 2021;35(3):552-562.

44. Carey ML, Zucca AC, Freund MA, Bryant J, Herrmann A, Roberts BJ. Systematic review of barriers and enablers to the delivery of palliative care by primary care practitioners. Palliat Med. 2019;33(9):1131-45.

45. Murray SA, Firth A, Schneider N, Van den Eynden B, Gomez-Batiste X, Brogaard T, et al. Promoting palliative care in the community: Production of the primary palliative care toolkit by the European Association of Palliative Care Taskforce in primary palliative care.

Palliat Med. 2015;29(2):101-11.

\section{Figures}

\section{Figure 1}

Flow chart describing the inclusion/exclusion of general practices and general practitioners (supplementing Figure 1 [22]) 